\title{
Contrast Enhanced Ultrasound (CEUS) and Off-label Use (in Children)
}

Prescribing pharmaceuticals for unapproved indications, or off-label use, is essential to therapeutic innovation, but it also raises questions about increased liability and pharmacovigilance. In Germany, an expert committee introduced the Statutory Health Insurance (SHI) Modernization Act of 2004 [1-3]. Two addendums were introduced in 2006; Annex 9 defines drugs that are eligible for off-label use, and Annex 10 lists drugs that will be eligible for prescription following assessment by the Institute for Quality and Efficiency in Health Care (IQWiG). The expert committee has also defined rules governing the Social Health Insurance (SHI)-financing and prescription of oncology therapeutics for unlicensed use, based upon a ruling from the Federal Social Court [2].

Despite these efforts, numerous problems regarding funding and other critical issues remain unsolved in the off-label use of drugs and imaging modalities, including ultrasound and ultrasound contrast agents (UCA) [1, 2].

The off-label use of contrast enhanced ultrasound (CEUS) illustrates the need to deal with unresolved legal issues and balance with the need for diagnostic innovation in the daily clinical routine [3]. CEUS has a number of distinct advantages over CT and MRI. It can be performed immediately, without any preliminary laboratory testing, and it can be carried out in a variety of settings (bedside, operatory room, CT suite, etc.). CEUS operates in real time, so that rapid changes can be captured, and without radiation exposure [4].

\section{Licensing of Contrast Agents in Eu- rope

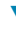

UCA registered in Europe are licensed only for cardiac or, in the case of SonoVue ${ }^{\circledR}$, for liver and vascular applications. SonoVue is used with ultrasound imaging to enhance the echogenicity of the blood, by improving signal to noise ratio; increase the accuracy in detection or exclusion of abnormalities in cerebral arteries and extracranial carotid or peripheral arteries by improving the Doppler signal to noise ratio (Doppler of macrovasculature); and increase the quality of the Doppler flow image and the duration of clinically-useful signal enhancement in portal vein assessment. SonoVue ${ }^{\circledR}$ also improves imaging of liver and breast lesion vascularity during Doppler sonography, leading to more specific lesion characterisation (Doppler of microvasculature) [5]. In addition to licensed indications with a focus on the liver and Doppler enhancement, SonoVue is safe [6] and effective [7] for examination of almost all organs, as recently published by European guidelines [4]. These published clinical recommendations on the use of CEUS are based on comprehensive literature surveys, including results from prospective clinical trials, and incorporate many indications currently off-label.

The current legal requirements for the registration of pharmaceutical products in Europe are strict. In order for a new indication to be registered, the manufacturer must provide data on safety and efficacy, with a dedicated phase III trial specifically designed to achieve that registration approval. Diagnostic agents, including contrast microbubbles, are no exception to this rule, which is designed to protect patients from the misuse of drugs or diagnostic agents but may limit the potential benefit to patients.

Applications for novel indications not only follow clinical or scientific needs, but also the financial expectations of the producer and health care funding entities. For some products, the marketing forecast of income from the additional indications is lower than the costs of a registration trial, so that new indications are unlikely to appear. In these cases, lack of registration does not equal lack of efficacy of a marketed compound used for an off-label indication. Patients could be individually informed to consider consenting to non-licensed investigations, which would be up to the discretion of the physician.

\section{Off-label Use in Children $\nabla$}

Off-label use is of utmost importance in pediatrics because many drugs are not tested by randomized trials in children, which also means that they are not specifically licensed for use in children [8]. Licensed drugs are often prescribed outside the terms of the product license in relation to age. Over two thirds (67\%) of 624 children admitted to wards in five European hospitals received drugs prescribed in an unlicensed or off-label manner and 39\% of the 2262 drug prescriptions given to children were off-label [9]. Licensed drugs 
for adults may only be used in children after the parents (or legal representatives) have been adequately informed, and specific consent has been obtained, with an exception for emergency cases. Diagnostic agents, including contrast microbubbles, are no exception to this rule [4]. Thus, before SonoVue ${ }^{\circledR}$ or any other agent can be used routinely in children, a dedicated trial which demonstrates efficacy and safety has to be performed. Until this happens the agent will remain off-label for pediatric use. Unfortunately, these rules, which are designed to protect patients, occasionally, limits the potential benefit to patients, if, for instance, a sonographer refuses to perform off-label indications.

There is one currently licensed indication for UCA in pediatrics; Levovist ${ }^{\circledR}$ (Bayer, Germany) is registered for vesico-ureteric studies. However, Levovist ${ }^{\circledR}$ has a limited market and its production has been discontinued [4], leaving an important diagnostic need unmet. In many clinics, this void is presently filled by the non-licensed SonoVue ${ }^{\circledR}$. This is just one example supporting the off-label use of UCA in children due to diagnostic benefits such as high efficacy and great overall safety.

For a more in depth examination of this subject I refer the reader to the recently published EFSUMB comments [10] on a recently published paper [11] and additional current literature [12].

\section{Off-label Use and Funding \\ $\nabla$}

In general, drugs that are neither not licensed for the pharmaceutical market, nor for a respective indication may not be prescribed by any physician except under clinical trial conditions or individual clinical advice. Sickness funds may not fund clinical research, cover prescriptions of unlicensed drugs, or cover unlicensed indications. In many countries only a timeconsuming, individual clarification process with the sickness fund may offer a solution [8;13-16].

Schreiber-Dietrich D, Department of Pediatrics, Klinikum Aschaffenburg, Aschaffenburg, Germany

Dietrich CF, Medizinische Klinik 2 Caritas Krankenhaus, Bad Mergentheim, Germany
1 Dietrich CF. [Elastography, the new Dimension in Ultrasonography]. Praxis (Bern 1994) 2011; 100 (25): 1533-1542.

2 Dietrich CF, Jenssen C. [Evidence based endoscopic ultrasound]. Z Gastroenterol 2011; 49 (5): 599-621.

3 Dietrich CF. Comments and illustrations regarding the guidelines and good clinical practice recommendations for contrast-enhanced ultrasound (CEUS)--update 2008. Ultraschall Med 2008; 29 Suppl 4: S188S202.

4 Piscaglia F, Nolsoe C, Dietrich CF, Cosgrove DO, Gilja OH, Bachmann NM et al. The EFSUMB Guidelines and Recommendations on the Clinical Practice of Contrast Enhanced Ultrasound (CEUS): Update 2011 on non-hepatic applications. Ultraschall Med 2011.

5 Claudon M, Cosgrove D, Albrecht T, Bolondi L, Bosio M, Calliada F et al. Guidelines and good clinical practice recommendations for contrast enhanced ultrasound (CEUS) - update 2008. Ultraschall Med 2008; 29 (1): 2844.

6 Piscaglia F, Bolondi L. The safety of Sonovue in abdominal applications: retrospective analysis of 23188 investigations. Ultrasound Med Biol 2006; 32 (9): 1369-1375.

7 Piscaglia F, Cucchetti A, Bolondi L. „Survival benefit": the final destination, with still a long way to go. Dig Liver Dis 2010; 42 (9): 608-610.

8 Henschel AD, Rothenberger LG, Boos J. Randomized clinical trials in children--ethical and methodological issues. Curr Pharm Des 2010; 16 (22): 2407-2415.

9 Conroy S, Choonara I, Impicciatore P, Mohn A, Arnell H, Rane A et al. Survey of unlicensed and off label drug use in paediatric wards in European countries. European Network for Drug Investigation in Children. BMJ 2000; 320 (7227): 79-82.

10 Nolsoe C, Piscaglia F, Dietrich CF, Gritzmann $\mathrm{N}$, Sporea I, ter Haar G. Primum non nocere? Why Can't We Use Second Generation Ultrasound Contrast Agents for the Examination of Children? Ultraschall in Med 2011; 32: 83-86.

11 Piskunowicz M, Kosiak W, Irga N. Primum non nocere? Why can't we use second generation ultrasound contrast agents for the examination of children? Ultraschall in Med 2011; 32 (1): 83-86.

12 Piskunowicz M, Kosiak W, Batko T. Intravenous Application of Second-Generation Ultrasound Contrast Agents in Children: A Review of the Literature. Ultraschall in Med 2012; 33 (2): 135-140.

13 Harder Y. [The physician caught between two chairs. Comments on the difficulty in dealing with off-label use]. Urologe A 2007; 46 (10): 1429-1434.

14 Hart D, Muhlbauer B. [Off-label use of drugs in paediatrics causes uncertainty]. Z Evid Fortbild Qual Gesundhwes 2008; 102(1): 37-43.

15 Henze G. Dose finding in pediatric patients. Ernst Schering Res Found Workshop 2007; (59): 111-121.

16 Hsien L, Breddemann A, Frobel AK, Heusch A, Schmidt KG, Laer S. Off-label drug use among hospitalised children: identifying areas with the highest need for research. Pharm World Sci 2008; 30 (5): 497-502. 